\title{
Cultura e turismo no espaço rural: limites e possibilidades
}

\author{
Culture and tourism in rural areas: limits and possibilities
}

\section{Clediane Nascimento Santos, Rosângela Custódio Cortez Thomaz}

\begin{abstract}
RESUMO
Este artigo tem o propósito de estudar o turismo e a cultura do espaço rural do município de Rosana (SP), localizada região do Pontal do Paranapanema. Consiste em considerar a cultura importante para o desenvolvimento social e econômico das comunidades envolvidas. Por meio de pesquisa qualitativa, de caráter descritivo e empírico, com estudo da literatura pertinente e mediante o uso de entrevistas semiestruturadas, com roteiro elaborado previamente e com questões em aberto, pois este tipo de entrevista possibilita mais flexibilidade à pesquisadora em inserir alguma questão sobre algum aspecto importante surgida no ato da entrevista, e que não tenha sido contemplada no roteiro. Os principias resultados obtidos até o presente momento foram as festividades identificadas nos assentamentos: Folias de Reis, festa de Aniversário da Gleba XV de Novembro, festa da Mandioca, Roda de Viola e as festas dos padroeiros, como Nossa Senhora Aparecida, Sagrado Coração de Jesus, Santa Luzia e São Francisco de Assis, e a agenda cultural de 2009, 2010 e 2012.
\end{abstract}

PALAVRAS-CHAVE: Assentamentos Rurais; Manifestações Culturais; Turismo no Espaço Rural.

\section{ABSTRACT}

This article aims to study the tourism and the culture at rural area of the municipality of Rosana/SP, localized at the Pontal Paranapanema region. It is about to consider the importance of culture for social and economic development of the communities involved.Through qualitative research, investigative and empirical character, with the study of literature and by using semi-structured interviews with pre-prepared script and open issues, because this type of interview allows more flexibility for the researcher to insert a question on some important aspect that emerged during the interview, and that has not been contemplated in the script. The main results obtained until now were the festivities identified at the settlements: Folias de Reis, Festa de Aniversário da Gleba XV de Novembro, Festa da Mandioca, Roda de Viola and the festivities Ikof patron saints, such as Nossa Senhora Aparecida, Sagrado Coração de Jesus, Santa Luzia and São Francisco de Assis, and the cultural agenda for 2009, 2010 and 2012.

KEYWORDS: Rural Settlements; Cultural Manifestation; Tourism in Rural Areas.

Página 958 Revista Brasileira de Ecoturismo, São Paulo, v.6, n.5, nov 2013-jan 2014, pp.958-97I. Sociedade Brasileira de Ecoturismo. Rua Dona Ana, 138, Vila Mariana, São Paulo, SP - Brasil. E-mail: rbecotur@sbecotur.org.br; Tel. (55-II) 99196-7685 


\section{Introdução}

O município de Rosana localizado no extremo oeste paulista, pertencente à microrregião de Presidente Prudente, está situado a $780 \mathrm{~km}$ da capital do Estado de São Paulo, fazendo parte da região conhecida como Pontal do Paranapanema.

A região do Pontal do Paranapanema é marcada pela concentração de assentamentos de reforma agrária e por esse motivo é um espaço muito assinalado ao longo dos anos por lutas e entraves territoriais. Desse modo, essa região constituise como um objeto importantíssimo de análise, pois é possível estudar além das questões de reforma agrária, os recursos naturais, culturais, técnico-científicos. Assim, se faz necessário compreender o desenvolvimento territorial local por meio da atividade do turismo, já que esta região faz parte do Programa Federal Território da Cidadania.

Os Territórios da Cidadania foram criados levando em consideração os seguintes critérios: sociais, culturais, geográficos e econômicos. São reconhecidos como o espaço historicamente construído, com a incidência de identidades que possibilitam conexão social, cultural e territorial. Além disso, o Território da Cidadania, busca a construção de políticas públicas interligadas ao planejamento territorial; participação social na gestão das políticas públicas com perspectiva ao desenvolvimento dos territórios; inclusão e integração produtiva das populações pobres e dos segmentos sociais mais vulneráveis, tais como trabalhadoras rurais, quilombolas, indígenas e populações tradicionais; valorização da diversidade social, cultural, econômica, política, ambiental entre outros (BRASIL, 2008).

Os documentos elaborados e disponibilizados no site do Território da Cidadania são relatórios que contemplam as ações executadas e as sugestões para melhorar e viabilizar a execução de outras ações. Essas ações têm como princípio o trabalho em conjunto entre os governos federal, estaduais, municipais e da sociedade civil, no intuito de assegurar a execução das ações e o desenvolvimento territorial dos municípios (BRASIL, 2011).

A partir disso, percebe-se que pouco se tem falado sobre o programa Território da Cidadania como colaborador do desenvolvimento local, bem como sua participação no espaço rural de Rosana (SP).

\section{Turismo no espaço rural}

O turismo é uma atividade que no mundo contemporâneo é visto como uma ferramenta para o desenvolvimento dos lugares. Seu início não é recente, mas há pouco tempo que alguns países vêm planejando a atividade como geração de capital financeiro.

Segundo Mariani (2007) o turismo é considerado um fenômeno por alguns motivos: o primeiro como social, pois envolve grande quantidade de indivíduos; o segundo por questões econômicas porque seu desenvolvimento é de grande importância dentro de uma sociedade; e terceiro devido a sua magnitude como fator de distribuição geográfica. 
Há uma gama de variações em relação à motivação turística, que é elaborada a partir dos desejos do ser humano em conhecer locais novos e paisagens que destoam de seu cotidiano. Dentre as tipologias das diversas segmentações existentes, podem ser citadas: turismo cultural, turismo náutico, turismo em áreas naturais, turismo no espaço rural, entre outros (PANOSSO NETO; ANSARAH, 2009).

A atividade de turismo no espaço rural, dada a proporção a que se chegou, suscitou em pesquisadores e estudiosos a busca por informações precisas, para melhor entender e conceituar esta atividade que dinamiza este espaço.

Para Rodrigues (2001), o turismo rural compreende dois grupos, ambos levam em consideração o patrimônio cultural. No primeiro, o turismo rural relaciona-se com aspectos históricos, em que prevalece o turismo tradicional, derivado ou não de atividades agrícolas e, no segundo, predomina a contemporaneidade, por referir-se a empreendimentos instalados da década de 1970, exemplificados por pousadas rurais, spas rurais, segundas residências.

Para conceituar o turismo rural é necessário levar em consideração as seguintes informações: paisagem, tipo de empreendimento, o roteiro, a origem, as motivações, o tempo para permanência, atividades desenvolvidas, entre outras, que facilitarão na identificação do tipo de turismo praticado (RODRIGUES, 2001). Dessa forma, diversas modalidades de turismo podem ser desenvolvidas no espaço rural, tais como ecoturismo, turismo de aventura, dentre outras.

Para uma atividade ser considerada turismo rural, é necessário que ela se identifique com as seguintes características: pequena produção, contato com a natureza, envolvimento com a cultura do campo. Agindo bem mais que uma complementação a atividade agrícola e fazendo funcionar o trinômio: viagem, turismo e lazer (RUSCHMANN, 2003). Sendo assim, o turismo rural pode ser um multiplicador econômico em cadeia para aqueles proprietários que investem no negócio, gerando renda para a localidade, incrementando uma rede com os prestadores de serviços e qualificação para o local.

Estes benefícios são gerados quando há uma política no meio rural que funcione. Caso contrário, o turismo no espaço rural quando é implantado numa conjuntura em que a política é ausente, com certeza terá problemas. Tendo em vista que as políticas agrícolas são insuficientes, e por isso muitos proprietários aderem a atividade, no entanto o turismo não pode solucioná-lo, mas aponta direcionamentos que amenizará a situação.

Segundo Zimmermann (2003) o turismo rural é um produto fundamentado na produção de serviços no meio rural, no qual atrai uma demanda específica de visitantes. Sendo este produto constituído por meio de hospedagem, culinária e gastronomia, clima, informação, lazer, história, entre outros.

O turismo rural é uma ferramenta que se utilizada corretamente trará desenvolvimento a comunidade rural, mas para obter este retorno é de suma importância a preocupação com uma série de fatores que vão desde a comunidade aos bens culturais, passando pelo processo e condições de sobrevivência na área 
rural. Nestas condições salienta Cavaco:

A crescente valorização do ambiente, da paisagem, do rústico, da história e do sossego sustenta oportunidades de turismo e de lazer no espaço rural, da montanha à planície, do interior ao litoral, a sua concretização está condicionada pela presença de população permanente, garantia da tradição e da preservação do meio e prestadora dos serviços requeridos. Em um ou em outro caso, os atores vieram de longe, mas, na maior parte, têm raízes e patrimônios locais, que não desprezam e que procuram valorizar através do acolhimento de visitantes. Alguns lugares estão, porém, de tal modo desertificados e abandonados que dificilmente serão capazes de responder às procuras de lazer.[...] (CAVACO, 2001, p.89-90).

Segundo Tulik (2004) o turismo rural é caracterizado pela pluralidade de práticas e serve também como complemento a renda advinda da agricultura e pecuária, é gerador de empregos que contribuem para a diminuição do êxodo rural, estimula a economia local e um dos seus mais sensíveis benefícios é a preocupação social existente no investimento por parte do poder público.

Para o Ministério do Turismo - MTur (BRASIL, 2008b), a conceituação de turismo no espaço rural engloba as diversas atividades desenvolvidas no meio rural, independente de suas especificidades, tais como: o turismo rural, o agroturismo e o turismo rural na agricultura familiar. É o conjunto de atividades comprometidas com as atividades agropecuárias e com a valorização do patrimônio cultural e natural como feições da oferta turística no meio rural. O conceito do Ministério do Turismo será adotado neste trabalho, pois é o mais adequado a proposta de turismo nos assentamentos, que englobe o turismo cultural.

Por meio do turismo no espaço rural é possível a junção de diversas atividades tais como o turismo ecológico, pedagógico, e o cultural e sua relação direta com o patrimônio e a identidade local. Desde apresentações culturais, folclore, modo de vida, a experiência do homem camponês, hábitos, costumes, tradições, entre outros. Nesse contexto, o visitante tende a visitar os lugares que se diferem do seu, com o desejo de conhecer as particularidades inerentes ao lugar (AVILA, 2009).

O turismo no espaço rural é um recurso, que pode ser utilizado para o bem como para o mal. Por isso a incessante busca por planejamento, para que este recurso seja usado favoravelmente em benefício da comunidade local, no fomento ao desenvolvimento local. Em sintonia, o programa Território da Cidadania poderia ser um parceiro no intuito de contribuir e fortalecer o espaço rural das comunidades assentadas. E quem sabe mediar a valoração desta identidade comunal em detrimento da discriminação e estigma existente em torno dos assentamentos de reforma agrária.

\section{Cultura}

Diante da importância da cultura para o turismo, no que diz respeito as motivações pela busca do conhecimento de diversas culturas e da possibilidade do turismo como vetor de valorização e preservação do patrimônio cultural, pode -se dizer 
que o turismo poderá ser um aliado para a promoção dos eventos culturais, valorizando e promovendo os bens materiais e imateriais da cultura. (BRASIL, 2006).

Dentre todas as suas características, pode-se afirmar que o turismo tem como elemento substancial para sua efetivação, as peculiaridades de cada local, as identidades, a cultura. Assim o espaço rural dos assentamentos de Rosana/SP, é um diferencial para o desenvolvimento da atividade turística. É um campo de possibilidade para a geração de renda, emprego, auto - estima, valoração da identidade e do modo de vida.

Valendo da importância da cultura e da diversidade cultural para o desenvolvimento das nações, a Conferência Geral da Organização das Nações Unidas (ONU) para Educação, a Ciência e a Cultura reforça que a diversidade cultural é uma característica de suma importância para a humanidade, por isso o seu patrimônio deve ser valorizado e cultivado em benefício de todos. Também salienta de que a diversidade cultural deverá criar um mundo rico que incida sobre o desenvolvimento responsável das comunidades, povos e nações. Dessa forma, a cultura deve ser um elemento primordial das políticas de desenvolvimento nacionais e internacionais, que tenha como objetivo a superação da pobreza. De forma sucinta pode ser dizer que a cultura aborda diversas formas, ela é dinâmica através do tempo e do espaço, representa múltiplas manifestações, em sua originalidade e pluralidade das diversas identidades, bem como representa as expressões culturais dos povos e das sociedades (ORGANIZAÇÃO DAS NAÇÕES UNIDAS, 2005).

Para Thompson (1998) a cultura pode ser entendida como:

[...] um conjunto de diferentes recursos, em que há sempre uma troca entre o escrito e o oral, o dominante e o subordinado, a aldeia e a metrópole; é uma arena de elementos conflitivos, que somente sob uma pressão imperiosa - por exemplo, o nacionalismo, a consciência de classe ou a ortodoxia religiosa predominante - assume a forma de um "sistema". E na verdade o próprio termo "cultura", com sua invocação confortável de um consenso, pode distrair nossa atenção das contradições sociais e culturais, das futuras e oposições existentes dentro do conjunto (THOMPSON, 1998, p.17).

Segundo Claval (2007) a cultura se confunde com as construções das próprias sociedades, pois suas raízes estão imersas na história, no qual reúne e comungam os mesmos símbolos, alianças, os mesmos hábitos alimentares, vestimentas, entre outros elementos. No qual a cultura pode ser entendida como:

A cultura aparece como um conjunto de gestos, práticas, comportamentos, técnicas, know-how, conhecimentos, regras, normas e valores herdados dos pais e da vizinhança, e adaptados através da experiência a realidades sempre mutáveis. A cultura é herança e experiência. Ela é também projeção em direção ao futuro. Os outros mundos dos alhures permitem julgar o presente e pensar o futuro: eles dão aos seres humanos o poder de julgar o real, de discernir entre o 
bem e o mal, de fazer escolhas e tomar decisões morais que a sociedade lhe oferece, e da sua experiência, horizontes futuros. Graças a esses horizontes, a cultura aparece mais como a força que dá a sua forma ao futuro que como uma repetição do passado (CLAVAL, 2003, p.163).

Partindo do potencial que a cultura tem de agregar valor econômico, observa-se, nisso, uma motivação das localidades para cuidar dele, sendo responsabilidade de todos os cidadãos à sua manutenção. Quanto mais diverso e singular for mais positivo será para o desenvolvimento do turismo.

Dessa forma salienta a ONU $(1985$, p.3) sobre as políticas culturais:

Tudo isso reclama políticas culturais que protejam, estimulem e enriqueçam a identidade e o patrimônio cultural de cada povo, além de estabelecerem 0 mais absoluto respeito e apreço pelas minorias culturais e pelas outras culturas do mundo. A humanidade empobrece quando se ignora ou se destrói a cultura de um grupo determinado.

Outra questão que envolve a cultura é o conhecimento que se precisa ter sobre identidade, pois não adianta ter vários bens culturais num local, se a população não se reconhece nele. É necessário ter esse vínculo de pertencimento entre comunidade e cultura que revelará a identidade do local.

Para as Nações Unidas, a identidade cultural é uma riqueza que possibilita a realização da humanidade, dos povos, salvaguardando seu passado e acolhendo as contribuições para o seu processo de criação e dinamização. Todas as culturas constitui-se patrimônio paras suas comunidades. A identidade cultural representa diálogo, intercâmbio de ideias e experiências, apreciação de outros valores e tradições (ONU, 1985).

Para Giddens (1991 apud CASTELLS, 2001, p.22-23) a identidade pode ser entendida como:

[...] o processo de construção de significado com base em um atributo cultural, ou ainda um conjunto de atributos culturais inter-relacionados, o (s) qual (is) prevalece $(\mathrm{m})$ sobre outras fontes de significado. Para um determinado individuo ou ainda um ator coletivo, pode haver identidades múltiplas. No entanto, essa pluralidade é fonte de tensão e contradição tanto na auto-representação quanto na ação social. [...] Identidades, por sua vez, constituem fontes de significado para os próprios atores, por eles originadas, e construídas por meio de um processo de individualização.

Segundo Hall (2005) a identidade é algo inacabado, em constante construção.

Assim, a identidade é realmente algo formado, ao longo do tempo, através de processos inconscientes, e não algo inato, existente na consciência no momento do nascimento. Existe sempre algo "imaginário" ou fantasiado sobre sua unidade. Ela permanece sempre 
incompleta, está sempre "em processo", sempre "sendo formada". (HALL, 2005, p. 38-39).

Partindo de uma perspectiva de desenvolvimento territorial, a inserção da atividade turística, tendo como fundamento os aspectos culturais dos assentamentos, pode ser traduzida em recurso para o fomento da atividade, pois compreende um modo de vida singular.

Há uma forte tendência para a visitação nos destinos de sol e de praia em virtude da concentração de infraestrutura para o turismo no litoral, com a presença de empreendimentos estrangeiros, mas, percebe-se que os bens patrimoniais podem colaborar para inverter essa lógica, contribuindo para disseminar o turismo em outros espaços, como por exemplo, o espaço rural.

\begin{abstract}
A exploração turística dos recursos patrimoniais permite inverter a forte tendência de concentração da oferta turística junto ao litoral, dispersando o turismo para o interior, para as pequenas cidades, com uma distribuição mais equitativa dos seus benefícios, funcionando assim como fator de criação de emprego e de revitalização das economias locais. Representa, também, benefícios evidentes no que concerne aos custos de preservação do patrimônio que, muitas vezes, não podem ser assegurados pelos poderes locais. Por outro lado, com frequência se reclama a utilização do patrimônio para fins turísticos para se fazer em face de um turismo massificado que ameaça as identidades locais. (THOMAZ, 2010, p. 39).
\end{abstract}

\title{
Desenvolvimento local
}

A dimensão cultural do desenvolvimento para a ONU desempenha um papel essencial, pois contribui para fortalecer a independência, a soberania e a identidade das nações. Geralmente o crescimento tem sido percebido por meio de dados quantitativos, deixando de lado a dimensão qualitativa, com as perspectivas espirituais e culturais, que são tão imprescindiveis para o desenvolvimento autêntico e o bem-estar da comunidade (ONU, 1985).

O desenvolvimento local é uma estratégia da própria comunidade, que tem na inserção de novas atividades econômicas uma forma de gerar renda e emprego. Enfim, um modo de garantir a sua sobrevivencia.

Para Beni (2007, p.139), o desenvolvimento local pode ser caracterizado como:

\begin{abstract}
Mais do que obter ganhos em termos da posição ocupada pelo sistema produtivo local na divisao internacional ou nacional do trabalho, o objetivo é buscar o bem-estar econômico, social e cultural da comunidade local em seu conjunto. Além de influenciar os aspectos produtivos (agropecuários, indústriais e de serviços), a estratégia de desenvolvimento procura também atuar sobre as dimensões sociais e culturais que afetam o bem-estar da sociedade. Isto leva a diferentes caminhos de desenvolvimento, conforme as características e as capacidades de cada economia e sociedade locais.
\end{abstract}


Na visão de Rodrigues (2007), essa busca por desenvolvimento é denominada de troca de sinergias, no qual a própria comunidade, por meio de ações inovadoras luta pelo desenvolvimento, quando afirma que:

De outro lado, sob uma ótica distinta, desenvolvem - se iniciativas baseadas em sinergias locais que redundam em projetos turísticos modestos, porém, criativos e inovadores que apresentam, todavia a oportunidade de envolvimento de diversos segmentos das comunidades hospedeiras, gerando benefícios que são apropriados localmente de forma mais equânime. É sem sombra de dúvida, neste modelo de implantação turística que pode-se relacionar o turismo ao patrimônio e á identidade cultural, uma vez que os recursos mobilizados ancoram-se no lastro social (RODRIGUES, 2007, p.16).

Para Coriolano (2001) o desenvolvimento está atrelado a idéia de distribuição igualitária das riquezas e recursos produzidos. Para ela o desenvolvimento perpassa o setor econômico, e deve ser pautado também nas relações humanas. Este é o mais difícil, pois requer a adoção de medidas e idéias que venham a contribuir com a prática social e sua organização tanto de produção quanto ao consumo.

Assim o desenvolvimento deve abranger todos os setores e todo o território, respeitando a especificidade local, regional e nacional. Lembrando que os territórios são demarcados pelas pessoas, que trazem as marcas das identidades, dos costumes, da política, da cultura, etc. É de fundamental importância atentar ao fato de como o território pode se desenvolver levando em consideração e respeitando a presença humana e suas interlocuções.

O desenvolvimento local deve transceder os padrões econômicos. Deve permitir alternativas que vislumbre o crescimento equitativo dos aspectos sociais, históricos e culturais. Assim, o desenvolvimento deve ponderar sobre os elementos endógenos que trazem os conflitos territoriais, a materialização da história, os símbolos, os costumes, o modo de vida da localidade.

\section{Posssibilidades e limites: alguns resultados}

Diante das análises das incursões no município em questão e nos assentamentos, chegou-se a alguns resultados, que configuram as possibilidades e os limites identificados.

As possibilidades identificadas seriam os atrativos turísticos já existentes neste município, tais como: o balneário municipal; a usina hidrelétrica Engenheiro Sergio Motta; o Museu de Memória Regional; o encontro dos rios Paranapanema com o rio Paraná; o marco Geodésico, o turismo de pesca, os assentamentos rurais Gleba XV de Novembro e Nova Pontal. Dessa maneira esses elementos são um campo de possibilidades para o desenvolvimento do turismo, mas que não são devidamente trabalhados, por isso, o limite para esta ação consiste na ausência do órgão público municipal em formalizar o turismo, especialmente com melhoria da infraestrutura básica e de apoio ao turismo; e nos assentamentos a presença da prefeitura seria 
no apoio a projetos de turismo no espaço rural, além de melhoria nas estradas de acesso.

Outro caminho poderia ser o fomento do Programa Território da Cidadania, logo que sua criação tem como finalidade o desenvolvimento territorial dos municípios que o compõem. Nesse sentido, Rosana (SP) poderia ser beneficiado com projetos de turismo que colaborasse para o desenvolvimento e a valorização da cultura local por meio de arranjos produtivos e economia solidária.

Este Programa, conforme foi investigado só atua nos municípios quando há uma participação dos gestores municipais, fato que de imediato impõe limite ao desenvolvimento local, e justifica a ausência de ações dessa natureza em Rosana, como ficou evidente nos relatórios de execução no período de 2008 a 2010 que foram analisados.

Outra possibilidade para o desenvolvimento turístico seria a criação de um ponto de informação ao turista, para informá-lo sobre os horários de funcionamento dos atrativos; a localização dos meios de hospedagem; informações sobre outros pontos de visitação, especialmente nos assentamentos.

Já existe a sinalização turística na cidade permitindo o deslocamento dos turistas, mas, tem como fator limitador que apenas a sinalização não desperta o interesse para outros pontos.

A usina hidrelétrica e Museu de Memória Regional poderiam ser melhor aproveitados. Seria uma alternativa, para se trabalhar o turismo em conjunto com as comunidades rurais. A estes visitantes poderiam ser divulgados um roteiro de visitação nos assentamentos, nos quais poderiam saborear a culinária, visitar as propriedades ou até mesmo apreciarem as manifestações culturais, se esta coincidir com a data das festas. Esses roteiros existem, mas não há essa integração com as visitas da Usina e o Museu, portanto, têm como fator limitador a ausência do espírito empreendedor da comunidade, da iniciativa privada e dos órgãos públicos.

No município de Rosana (SP) foram identificadas algumas ações culturais de 2009 a 2012, tais como: Projeto Semeando o Futuro IV; Ponto de Cultura "ISCAP pela Cultura"; e o Projeto Guri.

Essas ações culturais poderiam ser atreladas ao turismo, como por exemplo, os artesanatos produzidos pelos participantes do Projeto Semeando o Futuro IV e do Ponto de Cultura "Iscap pela Cultura". Não há artesanatos na cidade, em virtude disso, os artesanatos produzidos por estes projetos poderiam ser uma possibilidade a ser incorporado ao turismo local. A principal dificuldade em colocar isso em prática é a ausência de um órgão que fizesse a mediação entre essas instituições com a Usina e o Museu, já que são locais com o turismo formalizado, com uma média de aproximadamente 8 mil visitantes por ano e por isso um local estratégico para a divulgação dos artesanatos. Assim, além dos 
projetos atenderem a população local, traria também a geração de renda por meio da venda dos artesanatos produzidos.

Igualmente a musicalidade da orquestra de viola ministrada pelo Ponto de Cultura, ou pelos assentados que fazem aula de instrumentos musicais no Projeto Guri podem ser uma alternativa para incrementar o turismo local. Poderia ser elaborado um calendário de eventos mensal com a programação de apresentações para a orquestra e do Projeto Guri. Para isso seria importante a parceria com a prefeitura para concretizá-lo.

A criação de um calendário que reunisse as manifestações culturais existentes nos assentamentos seria importante, pois não se tem nada a respeito disso no município que seja voltado para área rural. Este calendário, ao ser formatado, contribuiria para que pessoas de outros lugares pudessem acompanhar as festas e incentivaria a cultura dos assentados. Este calendário poderia complementado com outras ações institucionais como, por exemplo, a inserção da sinalização turística nos assentamentos para facilitar a localização e o deslocamento.

A pesquisa junto a Prefeitura foi de vital importância para entender quais as ações que estão sendo realizadas em beneficio da área rural assentada do município de Rosana. Assim, foi constatado que não há um calendário festivo para este espaço e que seria importante a sua elaboração. A elaboração de um calendário para o meio rural seria uma ferramenta para a valorização da cultura assentada.

As festas identificadas como possibilidade para o turismo foram: Folias de Reis, Festa de Aniversário do assentamento Gleba XV de Novembro, Roda de Viola, as festas dos padroeiros, como Nossa Senhora Aparecida, Sagrado Coração de Jesus, Santa Luzia e São Francisco de Assis. Estas festividades são as que possuem potencialidade por possuírem as seguintes características: local fixo, comissão organizadora e periodicidade para a realização da festa.

Há outras festividades, mas não farão parte da proposta de calendário por não estarem organizadas. Como é o caso dos pequenos rodeios, provas de laços, os torneios de futebol, as festas juninas e outras festas do padroeiro de outros setores do assentamento Gleba XV de Novembro e Nova Pontal, pois não apresentam um local próprio para realização das atividades festivas.

Essas festas poderão fazer parte da proposta de calendário oficial do município para o espaço rural, ou seja, dos assentamentos Gleba XV de Novembro e Nova Pontal. Esse calendário poderá tornar mais visível à realização dessas festividades e sua devida valorização.

As festividades identificadas nos assentamentos Gleba XV de Novembro e Nova Pontal, mesmo aquelas que não farão parte do calendário festivo (Quadro 1), representam a produção cultural dos assentados, o seu modo de vida, a identidade dos assentados, os costumes, a dança, a música, entre outros. 
Quadro 1: Calendário festivo rural de Rosana (SP).

Table 1: Festive Rural Calendar of Rosana (SP, Brazil).

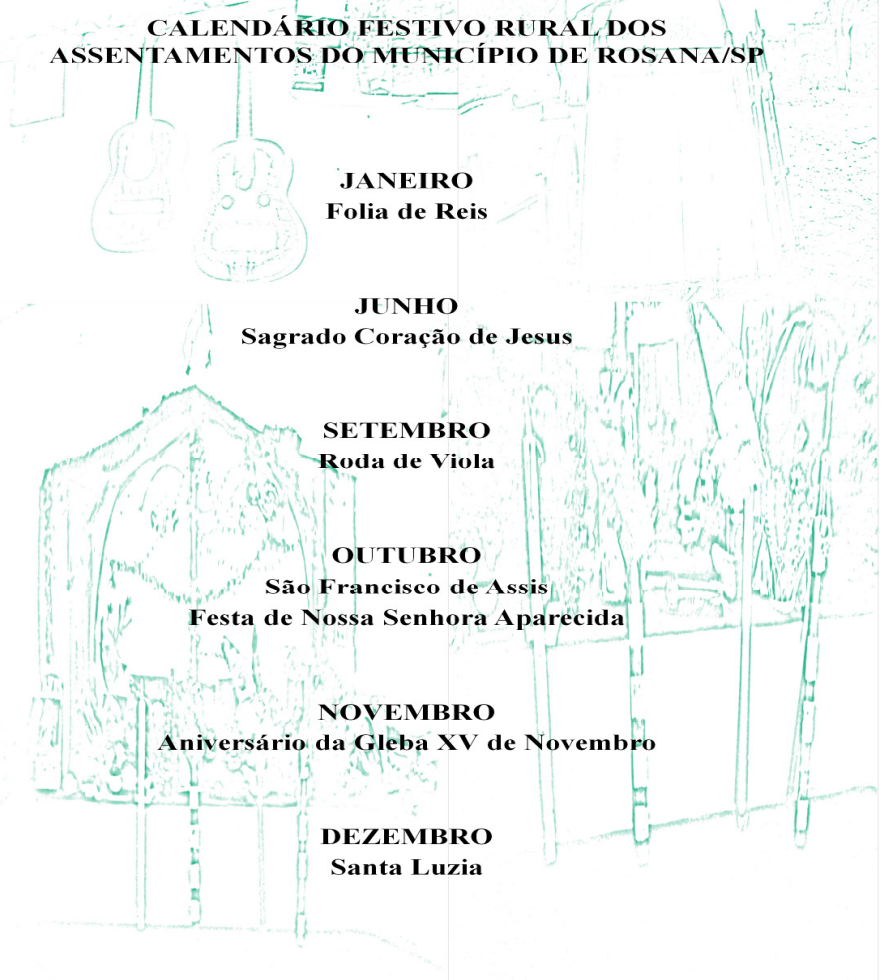

\section{Conclusão}

Os assentamentos de reforma agrária de Rosana/SP apontam para as interações entre as condições naturais e as diferentes formas de uso e ocupação deste território. Isso nos permite afirmar que a partir do olhar sobre as manifestações culturais representadas nas festas, estas consituem - se em motivações para o tursimo, ou seja, não só o patrimônio histórico-arquitetônico que tem levado as pessoas a deslocar - se como busca de conhecimento ou lazer, mas também as manifestações culturais ditas populares. São exequivies as alternativas que visem o desenvolvimento territorial local, seja ele catalisado na atividade turística ou não.

Além disso, outro caminho para o desenvolvimento do turismo local é a ligação que poderá existir com o programa Território da Cidadania, por meio da criação de arranjos produtivos ou de economia solidária com projetos que propicie o desenvolvimento turístico. Um programa como esse, forte e de abrangência federal tem potencialidade para contribuir para o crecimento desta localidade, possibilitar a dinamização da economia local e a valoração dos seus aspectos culturais. 
Para finalizar, o turismo no espçao rural viria a complementar a renda advinda da atividade agropecuária, além do mais contribuiria para fixar os moradores nos lotes, pois a maioria dos assentados sai para trabalhar no corte da cana-de-açúcar, pois o que produz não dá para fazer a manutenção no sistema de produção. Dessa forma, além de agregar valor, e gerar renda, motivaria para a salvaguarda da sua cultura e do seu modo de vida.

\section{Referências bibliográficas}

AVILA, M.A. Política e planejamento em cultura e turismo: reflexões, conceitos e sustentabilidade. In: AVILA, M.A. (Org.). Política e planejamento em cultura e turismo. Ilhéus: Editora UESC, 2009. p.15-37.

BENI, M. Planejamento estratégico e gestão local/regional do turismo. In: SEABRA, G. (Org.). Turismo de base local: identidade cultural e desenvolvimento regional. João Pessoa: Editora Universitária, 2007. p. 125- 150.

BRASIL. Decreto n. 38, de 25 de fevereiro de 2008. Dispõe sobre a instituição dos territórios da cidadania e dá outras providências. Brasília, DF, 2008a. Disponível: <http://ftp.saude.sp.gov.br/ftpsessp/bibliote/informe eletronico/2008/ iels.fev.08/iels39/U DC 250208.pdf>. Acesso em: 17 out. 2011.

BRASIL. Ministério do Turismo - MTur. Projeto Inventário da Oferta Turística. Brasília, 2006. Disponível em: <http://www.turismo.gov.br/export/sites/default/ turismo/o ministerio/publicacoes/downloads publicacoes/ inventariacao da oferta turistica.pdf>. Acesso em 20 jan. 2013.

BRASIL. Ministério do Turismo - MTur. Turismo rural: orientações básicas. Brasília, 2008b. Disponível em: <http://www.turismo.gov.br/export/sites/default/ turismo/o ministerio/publicacoes/downloads publicacoes/ Turismo Rural Versxo Final IMPRESSxO .pdf>. Acesso em 20 jan. 2013.

BRASIL. Território da Cidadania. Apresentação sobre o programa Territórios da Cidadania. Brasília, DF, 2011. Disponível em: < www.territoriosdacidadania.gov.br/dot/rn/clubs/territriosrurais/xowiki/portlets/ territorios/pages/folder-chunk>. Acesso em: 08 mai. 2012.

CASTELLS, M. O poder da identidade. 3. ed. Tradução de Klaus Brandini Gerhardt. São Paulo: Paz e Terra, 2001. v. 2.

CAVACO, C. Turismo, comércio e desenvolvimento rural. In: ALMEIDA, J A.; RIEDL, M. (Orgs.). Turismo rural: ecologia, lazer e desenvolvimento. Bauru: Edusc, 2001.p.69-94.

CLAVAL, P.A contribuição francesa ao desenvolvimento da abordagem cultural na geografia. In: CORRÊA, R.L.; ROSENDAHL, Z. (Orgs). Introdução à geografia cultural. Rio de janeiro: Bertrand, 2003. p. 147-166. 
CLAVAL, P. A geografia cultural. 3.ed. Florianópolis: Ed. UFSC, 2007.

CORIOLANO, L.N.T. Os limites do desenvolvimento e do turismo. Boletim Goiano de Geografia. Goiânia, v. 21, n. 2: Jul./Dez., 2001. Disponível em: <http:// www.revistas.ufg.br/index.php/bgg/article/view/4212>. Acesso em 11 Jun. 2012.

HALL, S. A identidade cultural na pós-modernidade. Rio de Janeiro: DP\&A, 2005.

MARIANI, M. Planos municipais de turismo no Brasil. In: SEABRA, G. (Org.). Turismo de base local: identidade cultural e desenvolvimento regional. João Pessoa: Editora Universitária, 2007. p. 211- 224.

ORGANIZAÇÃO DAS NAÇÕES UNIDAS - ONU. Declaração do México. [ S.I], 1985. Disponível em: <http://www.icomos.org.br/cartas/ Declaracao do Mexico 1985.pdf >. Acesso em 20 out. 2012.

ORGANIZAÇÃO DAS NAÇÕES UNIDAS - ONU. Proposta de Decisão do Conselho relativa à celebração da convenção da UNESCO sobre a proteção $e$ a promoção da diversidade das expressões culturais. Bruxelas, 2005. Disponível em: <http://www.unesco.pt/pdfs/docs/convdiv.pdf>. Acesso em 20 out. 2012.

PANOSSO NETO, A.; ANSARAH, M.G.R. Segmentação em turismo: panorama atual. In. PANOSSO NETTO, A.; ANSARAH, M.G.R. (Eds.). Segmentação do mercado turístico: estudos, produtos e perspectivas. Barueri: Manole, 2009. p. 19 $-43$.

RODRIGUES, A.B. Turismo rural no Brasil: enasaio de uma tipologia. In: RODRIGUES, A.B. (Og.). Turismo rural. São Paulo: Contexto, 2001.p.101-116.

RODRIGUES, A.B. Território, patrimônio e turismo com base local - uma relação inequivoca. In: SEABRA, G. (Org.). Turismo de base local: identidade cultural e desenvolvimento regional. João Pessoa: Editora Universitária, 2007. p. 15- 30.

RUSCHMANN, D.V.M. O turismo rural e o desenvolvimento sustentável. In: ALMEIDA, J.A.; FROEHLICH, J.M; RIEDL, M. (Orgs.). Turismo rural e desenvolvimento sustentável. Campinas: Papirus, 2003.p.63-73.

THOMAZ, R.C.C. A revalorização e difusão do patrimônio cultural como meio desenvolvimento do turismo rural e cultural: estudo de caso da rede galega do patrimônio arqueológico. Tópos. v. 4, n. 2, p. 33 - 59, Dez, 2010. Disponível em:<http://revista.fct.unesp.br/index.php/topos/article/view/2254>. Acesso em 20 jun 2013.

THOMPSON, E.P. Costumes em comum. São Paulo: Companhias das Letras, 1998.

TULIK, O. Turismo rural. São Paulo: Aleph, 2004. (Coleção ABC do turismo). 
ZIMMERMANN, A. Planejamento e organização do turismo rural no Brasil. In: ALMEIDA, J.A.; FROEHLICH, J.M; RIEDL, M. (Orgs.). Turismo rural e desenvolvimento sustentável. Campinas: Papirus, 2003. p.127-142.

Clediane Nascimento Santos: Universidade Estadual Paulista "Julio de Mesquita Filho", Presidente Prudente, SP, Brasil.

Email: cledianenascimento@yahoo.com.br

Link para o currículo Lattes: http://lattes.cnpq.br/3119695706223129

Rosângela Custódio Cortez Thomaz: Universidade Estadual Paulista "Julio de Mesquita Filho", Presidente Prudente, SP, Brasil.

Email: rocortez@rosana.unesp.br

Link para o currículo Lattes: http://lattes.cnpq.br/9063800080265540

Data de submissão: 30 de junho de 2012

Data de recebimento de correções: 24 de junho de 2013

Data do aceite: 20 de setembro de 2013

Avaliado anonimamente 